\title{
Theoretical and Experimental Research of Error of Method of Thermocouple with Controlled Profile of Temperature Field
}

\author{
Su Jun ${ }^{1}$, O. Kochan ${ }^{2}$, Wang Chunzhi ${ }^{1}$, R. Kochan ${ }^{2}$ \\ ${ }^{1}$ School of Computer Science, Hubei University of Technology, Hubei, China, sjhosix@gmail.com, \\ ${ }^{2}$ Institute of Computer Technologies, Automation and Metrology, Lviv Polytechnic National University, Bandera Str. 12 , \\ 79013, Lviv, Ukraine, orestvk@gmail.com, kochan.roman@gmail.com.
}

\begin{abstract}
The method of study and experimental researches of the error of method of the thermocouple with controlled profile of temperature field along the main thermocouple are considered in this paper. Experimentally determined values of error of method are compared to the theoretical estimations done using Newton's law of cooling. They converge well.
\end{abstract}

Keywords: Thermocouple, inhomogeneity of thermocouple, controlled profile of temperature field, measurement error, error of method.

\section{INTRODUCTION}

$\mathrm{T}$ EMPERATURE is one of the most frequently measured physical quantities. According to [1]: Statistical data show that the percentage of temperature measurements is $40 \%$ of all measurements in industry. In some branches of industry this percentage may be even considerably higher, in particular in power industry it equals about $70 \%$. That is why so many methods and sensors for temperature measurements exist [1], [2]. However, technological progress is challenging for existing measuring methods and expands the need for measurements in new conditions [3][6]. At the same time, requirements for accuracy of measurements are increasing in industry and areas, where temperature has been measured for a long time [1], [2], [7][9].

Despite the variety of existing sensors, thermocouples (TC) dominate in measuring praxis [1], [2]. Among the TCs the most popular are base and refractory metal TCs [1], [2], [10]. Noble metal TCs are used mostly as reference sensors [1], [2], [10]. All TCs of all kinds without exception are prone to degradation processes of their thermoelectrodes [11]-[15].

Degradation processes run in the electrodes of TCs during operation under the impact of the operating temperatures and time. Their rate is function of the temperature at which certain sections of TC are used. That is why thermoelectric inhomogeneity of thermoelectrodes is gradually growing.

Thus, the phenomenon of degradation of TC electrodes causes two interrelated temperature measurement errors [15]:

1. Error due to drift of conversion characteristic (CC) of TC (the change of CC with time) [15], [16];

2. Error due to the change of the generated thermo-emf when the distribution of the temperature along TC electrodes changes (temperatures of the reference and measuring junctions remain the same) [7], [15], [17], [18].

A lot of effort has been directed to correct the first kind of error using periodic verification [8] or calibration [19] of TC and drift prediction [20]. However, this way does not lead to considerable improvement of accuracy due to thermoelectric inhomogeneity of TC electrodes [15]. To solve this problem the methods of verification [8] or calibration [19], [21] in situ as well as their combination have been developed. However, these methods are efficient just when the temperature field along TC electrodes is steady. That is why the study of TC error in conditions of changeable temperature field along TC electrodes (error due to inhomogeneity) has been made in [7], [15], [18], [22].

The first known paper devoted to problems of thermoelectric inhomogeneity was written in 1906 [23], and the first known review and generalization of the existing methods for investigating inhomogeneity was made in [24]. A lot of time passed since then, but the problem is still topical [7] despite quite a big number of investigations of inhomogeneity of TCs [11]-[17], [25]-[27].

\section{THERMOCOUPLE WITH CONTROLLED PROFILE OF TEMPERATURE FIELD}

The method of rejection of impact of changes in temperature field of measuring object on temperature distribution along TC electrodes is stabilization of the temperature field of TC measuring the temperature of the object. Such a stabilization of the temperature field along TC electrodes eliminates appearance of inhomogeneity of these thermoelectrodes. Hence, the changes in the generated thermo-emf of inhomogeneous TCs due to the change of temperature field profile along them do not occur.

This method applies to a new TC based sensor, called thermocouple with controlled profile of temperature field (TCPTF) [28].

The TCPTF consists of the main TC (MTC) and several temperature control subsystems that are located along it to stabilize the temperature field of its electrodes (see Fig.1.), so that error due to inhomogeneity of MTC cannot distort readings. The system using TCPTF for temperature measurements and its errors is considered in [28].

However, the design of TCPTF is prone to the error caused by the heat flux $q$ (see Fig.1.) from the first heater toward the measuring junction of MTC. This error can be classified as an error of method. There are two measures applied to reduce the impact of error of method, that is to make the MTC able to measure the undistorted temperature of environment $T_{S}$ : 
1. measuring junction of MTC should be located relatively far apart from the closest heater $\mathrm{H} 1$ (the ratio $L_{1}$ to the MTC thermowell diameter is bigger than 10);

2. the temperature of heater H1 (its setpoint) should be equal to the temperature of measuring junction of MTC.

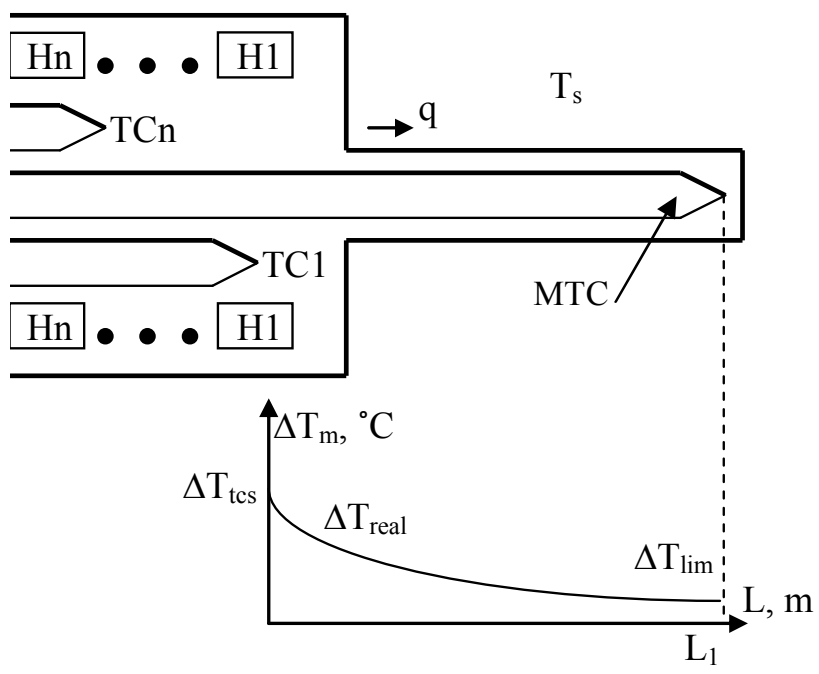

Fig.1. Design of TCPTF and the reason of error of method.

Therefore in an ideal TCPTF the heat flux $q$ due to lack of temperature difference across $L_{1}$ is absent, and consequently, error of method equals zero. However, some dispersions in CC of thermocouples MTC and TC1 [29] exist, due to which temperature difference $\Delta \mathrm{T}_{\mathrm{TCS}}$ across $L_{1}$ is not zero (see Fig.1., where the situation with maximum error of method is given), consequently, the heat flux $q$ and error of method appear. MTC and TC1 are of the same type of thermocouples and their tolerance [29] is $\Delta T_{T C}$, so the temperature difference $\Delta T_{T C S}$, which calls error of method across $L_{1}$ is

$$
\Delta T_{T C S}=\sqrt{2} \Delta T_{T C}
$$

Because of the heat exchange between the environment with the temperature $T_{S}$ and the surface of MTC thermowell (see the right part of Fig.1.), the temperature difference between the environment and the electrodes of the MTC across $L$ is described by the curve $\Delta T_{R E A L}$. Hence, the value $\Delta T_{L I M}$ at position $L_{1}$ is the maximum value of error of method of the proposed TCPTF.

\section{ANALYTICAL ESTIMATION OF ERROR OF METHOD}

It is a very complex task to find $\Delta T_{L I M}$ on the basis of static distribution of temperature. However, it is not necessary to determine the whole curve $\triangle T_{R E A L}$ (see Fig.1.). To estimate the upper limit of error of method $\Delta T_{L I M}$ it is enough to estimate the change of temperature at the point $L_{1}$, which corresponds to the magnitude of error of method $\Delta T_{L I M}$. That is why the method for estimating
$\Delta T_{\text {LIM }}$ based on its dynamic change of temperature difference $\Delta T_{T C S}$ has been developed.

Let us assume the temperatures of heater $\mathrm{H} 1$ and the measuring junction of the MTC are the same $\left(\Delta T_{T C S}=0\right)$. Then at a certain moment heater $\mathrm{H} 1$ abruptly increases its temperature and subsequently the temperature difference between its temperature and the temperature of MTC becomes equal maximum magnitude of $\Delta T_{T C S}$ (see Fig.1.). To describe the coming transition process, Newton's law of cooling is used [30]. Theoretically, this above mentioned transition process never ends, but it is enough to estimate the limit of it, as time approaches infinity. This limit corresponds to the error of method $\Delta T_{L I M}$ which is caused by temperature difference $\Delta T_{T C S}$ between heater $\mathrm{H} 1$ and the measuring junction of MTC.

Let us write the heat balance equation for the thermowell of the MTC to estimate error of method $\Delta T_{L I M}$. Heater H1 emits the amount of heat flux $q$ during time $d t$. The heat is absorbed by the metal thermowell and rises its temperature on $d T$ as well as the heat is dissipated in environment with temperature $T_{S}$ (see Fig.1.). According to Newton's law of cooling [30], let us write the differential equation for the steady state mode to determine the dependence of temperature of thermowell $T$ on time $t$

$$
q d t=c V \rho d T+\alpha A\left(T-T_{S}\right) d t
$$

where $q$ - heat flux due to temperature difference between heater $\mathrm{H} 1$ and the measuring junction of the MTC; $c$ specific heat capacity of thermowell material of the MTC; $V$ - volume of the thermowell of the MTC; $\rho$ - density of thermowell material of the MTC; $\alpha$ - heat transfer coefficient of steel to air; $A$ - the area of external surface, which is in thermal contact with the environment, that is the area of thermowell of the MTC [31].

Notice that (2) assumes that the heater H1 is not on the edge of the thermowell (as seen in Fig.1.), but it is in its center. However, such an improper treatment of (2) does not cause a significant error of estimation, when the heat flux $q$ emitted by $\mathrm{H} 1$ under the impact of $\Delta T_{T C S}$ corresponds to the real one. Then the estimation of error of method is going to be slightly overstated, which is acceptable. We calculate the heat flux $q$ using the formula [30], [32]

$$
q=\frac{\lambda \Delta T_{T C S} A_{N}}{L_{1}}
$$

where $\lambda$ - thermal conductivity of the thermowell material of the MTC; $\Delta T_{T C S}$ - the temperature difference between heater $\mathrm{H} 1$ and the measuring junction of the MTC; $A_{N}-$ the area of the surface through which heat flux is transmitted (cross section area of the thermowell); $L_{1}$ - distance from heater $\mathrm{H} 1$ to the measuring junction of the MTC [31]. 


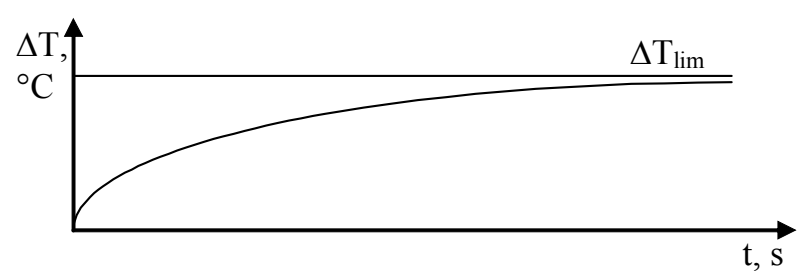

Fig.2. The change of error of method $\Delta T_{L I M}$ in time under the temperature jump of heater $\mathrm{H} 1$.

Solution of (2) with respect to temperature of the thermowell, thus with respect to the temperature of the measuring junction of the MTC gives a function of time.

$$
T=T_{S}+\frac{q}{\alpha A}\left(1-e^{-\frac{\alpha A}{c V \rho} t}\right)
$$

In (4), the term $\frac{q}{\alpha A}\left(1-e^{-\frac{\alpha A}{c V \rho} t}\right)$ actually corresponds to the error of method $\Delta T_{L I M}$, and describes the change of error of method in time (see Fig.2.). If time $t$ approaches infinity, then the term $e^{-\frac{\alpha A}{c V \rho} t}$ approaches zero. Thus, the upper limit of error of method $\Delta T_{L I M}$ asymptotically approaches its limit [31]

$$
\Delta T_{\lim }=\lim _{t \rightarrow \infty} \frac{q}{\alpha A}\left(1-e^{-\frac{\alpha A}{c V \rho} t}\right)=\frac{q}{\alpha A}
$$

\section{DEPENDENCE OF ERROR OF METHOD ON MEASURED TEMPERATURE}

As it is shown in (2) - (5), error of method $\Delta T_{L I M}$ depends on several variables. We estimate its value for a specific pattern of TCPTF using type $\mathrm{K}$ TC which has a body made of stainless steel [28]. For such a sensor [32]

$$
\begin{gathered}
A_{N}=6.3 \times 10^{-5} m^{2} ; L=0.15 m, A=5.5 \times 10^{-3} \mathrm{~m}^{2}, \\
\alpha=44 \frac{W}{m^{2} \times K} ; \\
\lambda=14.2 \frac{W}{m \times K}
\end{gathered}
$$

The allowable deviation of $\mathrm{CC}$ of $\mathrm{TC}$ from the nominal one depends on the temperature $\mathrm{T}_{\mathrm{s}}$. According to [29], the tolerance of CC $\Delta T_{T C}$ for the type $\mathrm{K} \mathrm{TC}$ is

$$
\left\{\begin{array}{l}
\Delta T_{T C}= \pm 2.5^{\circ} \mathrm{C} \text { for temperatures } 40-333^{\circ} \mathrm{C} ; \\
\Delta T_{T C}= \pm 0.0075|T| \text { for temperatures } 333-1200^{\circ} \mathrm{C} .
\end{array}\right.
$$

We plug the values $\Delta T_{T C S}$ to (3) and obtain a set of data plug to (5). Calculations give us the dependence of the upper limit of error of method $\Delta T_{L I M}$ on measured temperature $T_{S}$ (see Fig.3.). It is obvious from the plot, $\Delta T_{L I M}$ is a function of the tolerance of TC $\Delta T_{T C}$. The upper limit of $\Delta T_{\text {LIM }}$ grows linearly for temperatures over $333^{\circ} \mathrm{C}$.

For lower temperatures, the upper limit of error of method $\Delta T_{\text {LIM }}$ remains constant, as for type $\mathrm{K} \mathrm{TC}$ in this range the tolerance $\Delta T_{T C}$ remains constant as well.

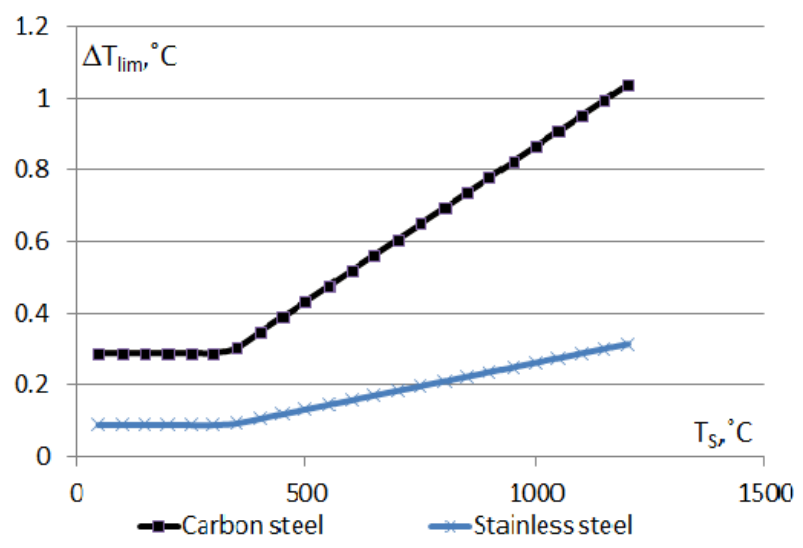

Fig.3. Dependence of error of method $\Delta T_{L I M}$ on measured temperature $T_{S}$.

\section{METHOD OF THE EXPERIMENTAL STUDIES}

All existing theoretical approaches to describe temperature distributions in rigid bodies are based on simplifications in physical processes which is a considerable obstruction for adequate description of temperature distributions in studied bodies. So, recently the main accent in studying temperature fields is made on experimental data which are processed later using theoretical means [33]. However, despite these drawbacks of theoretical approaches, they allow evaluating not just temperature distribution in studied bodies but also discovering consistent patterns inherent to particular thermal processes and outlining ways of purposeful control of them.

As the theoretical estimation has shown, the value of error of method of TCPTF does not exceed a few tenths of a Celsius degree. Since the error of the thermocouples is much larger than the error of method of TCPTF, the direct measurement of this error is impossible. That is why it is proposed to use the relative method of measurements to solve the problem. It is based on measuring the changes in temperature which occur when changing the power of the heater H1 (see Fig.1.). Then, each change of the temperature is measured by the same measuring channel. Namely, the systematic error of each channel in measuring small changes will affect only the temperature and will not practically affect the measured change. The systematic component of the measurement error will be mutually adjusted. Since the outcome of the experiment may be affected by some random temperature changes of the environment during the experiment time, the measuring junction of the MTC is placed into the passive thermostat. Its temperature is measured by an additional resistance temperature detector (RTD). 
The general scheme of the experimental research of error of method is shown in Fig.4. The block diagram of TCPTF is in the top part of Fig.4. It shows all the sensors participating in the experiment - thermocouples (the MTC and the first zone of heating TC1) and the RTDs (of reference junctions $\mathrm{R}_{\mathrm{T}} 1$ and of the passive thermostat of measuring junctions $\mathrm{R}_{\mathrm{T}} 2$ ). At the bottom of Fig.4. the scheme of measurements' running is shown. During the first stage of the experiment, all the heaters are off. The temperature of all the sensors is the same as in the ambient air. It is necessary to measure the temperatures of all sensors several times and to check if their temperatures do not change more than random error of measurement channels.
During the second stage of the experiment the heater of zone 1 is run at full power. This causes the temperature change of the first heating zone, measured by TC1. After a while the heat flux from the heater of zone 1 will change the temperatures of the measuring junction of MTC and its passive thermostat. One must periodically measure these temperatures until they are steady (transition process of heating comes to the end). Since the transition processes are long-lasting during the temperature change, it is necessary to take into account possible changes of temperature in the thermostat of their reference junctions during the temperature measurement with thermocouples.

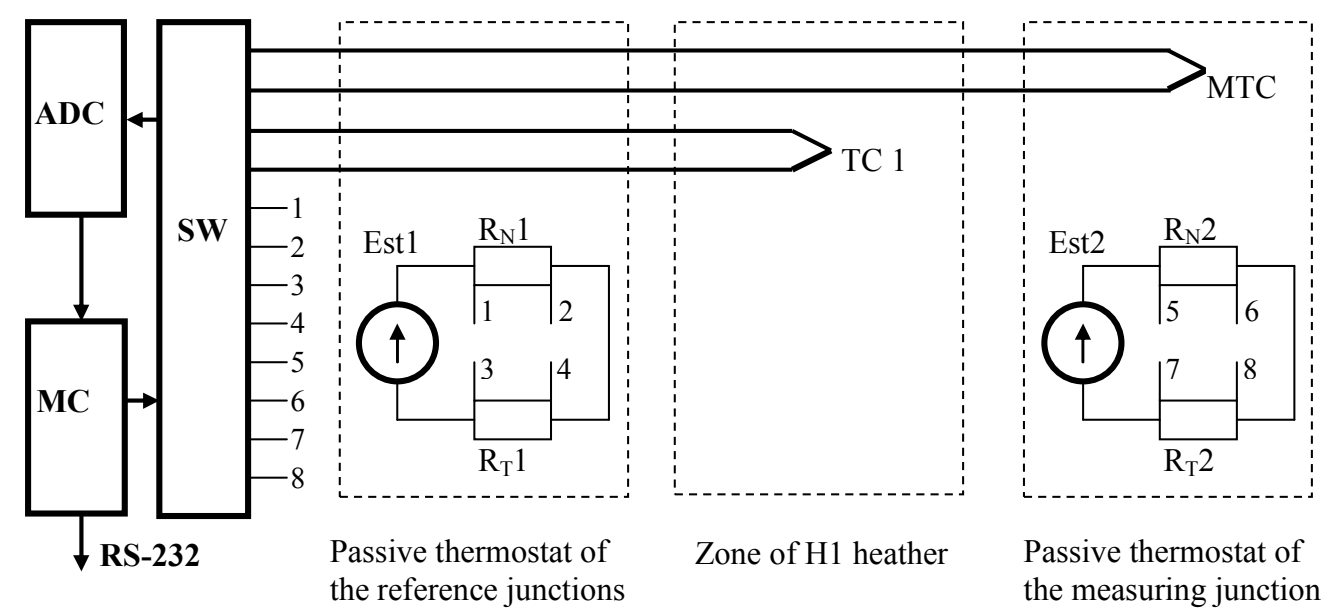

\begin{tabular}{|c|c|c|c|c|c|}
\hline \multirow[t]{2}{*}{$\begin{array}{l}\text { The 1-st stage } \\
\text { of experiment }\end{array}$} & $\begin{array}{c}\text { Reference junctions' } \\
\text { temperature before heating } \\
\text { of the } 1 \text {-st zone }\end{array}$ & $\begin{array}{c}\text { Temperature of the 1-st } \\
\text { zone before heating }\end{array}$ & \multicolumn{2}{|c|}{$\begin{array}{l}\text { Measuring junction's } \\
\text { temperature before heating } \\
\text { of the } 1 \text {-st zone }\end{array}$} & \\
\hline & change & \multicolumn{2}{|l|}{ change } & \multicolumn{2}{|c|}{$\begin{array}{c}\text { Thermostat's } \\
\text { temperature before } \\
\text { heating of the 1-st zone }\end{array}$} \\
\hline $\begin{array}{l}\text { The 2-nd stage } \\
\text { of experiment }\end{array}$ & $\begin{array}{l}\text { Reference junctions' } \\
\text { temperature after heating of } \\
\text { the } 1 \text {-st zone }\end{array}$ & $\begin{array}{l}\text { Temperature of the } 1 \text {-st } \\
\text { zone after heating }\end{array}$ & \multicolumn{2}{|c|}{$\begin{array}{c}\text { Measuring junction's } \\
\text { temperature after heating } \\
\text { of the 1-st zone }\end{array}$} & change \\
\hline & & & & \multicolumn{2}{|c|}{$\begin{array}{c}\text { Thermostat's } \\
\text { temperature after } \\
\text { heating of the 1-st zone }\end{array}$} \\
\hline
\end{tabular}

Fig.4. General scheme of the experimental research.

According to the scheme of Fig.4., the instruction of the experimental research is compiled:

1. To place the reference junction of TCPTF into the passive thermostat, where also the RTD is placed, and connect the circuit of Fig.4. To keep TCPTF indoors without heating zones during the whole day;

2. To measure (without turning on the heaters) ambient temperature $T_{S}$, voltage drops $U_{R N 2}$ across the reference resistor $R_{N} 2$, and $U_{R T 2}$ across the RTD $R_{T} 2$ of the reference junctions, thermo-emfs of the thermocouple of the first zone $E_{1 Z}$ and MTC $E_{G T}$, voltage drops $U_{R N 1}$ across the reference resistor $R_{N} 1$, and $U_{R T 1}$ across the RTD $R_{T} 1$ of the passive thermostat;
3. To turn on the full power of the first heating zone, to keep TCPTF in these conditions for six hours;

4. To measure ambient temperature $T_{S Z}$, voltage drops $U_{R N 2 Z}$ across the reference resistor $R_{N} 2$, and $U_{R T 2 Z}$ across the RTD $R_{T} 2$ of reference junctions, thermo-emfs of the thermocouple of the first zone $E_{1 Z Z}$ and the main thermocouple $E_{G T Z}$, voltage drops $U_{R N 1 Z}$ across the reference resistor $R_{N} 1$, and $U_{R T 1 Z}$ across RTD $R_{T} 1$ of the passive thermostat;

5. To calculate resistance of the RTDs $R_{T} 1$ and $R_{T} 2$ before the heating of the first zone and $R_{T} 1_{Z}$ and $R_{T} 2_{Z}$, respectively after its heating by the formulas 


$$
\begin{gathered}
R_{T} 1=R_{N} 1 \cdot \frac{U_{R T 1}}{U_{R N 1}}, R_{T} 2=R_{N} 2 \cdot \frac{U_{R T 2}}{U_{R N 2}}, \\
R_{T} 1_{Z}=R_{N} 1 \cdot \frac{U_{R T 1 Z}}{U_{R N 1 Z}}, R_{T} 2_{Z}=R_{N} 2 \cdot \frac{U_{R T 2 Z}}{U_{R N 2 Z}},
\end{gathered}
$$

where $R_{N} 1=160.7 \Omega$ and $R_{N} 2=109.83 \Omega$;

6. To calculate the temperatures of the reference junctions before the heating of the first zone and after its heating $T_{V K}$ and $T_{V K Z}$, respectively by the formulas

$$
T_{V K}=\frac{R_{T} 2-R_{0} 2}{\alpha \cdot R_{0} 2}, \quad T_{V K Z}=\frac{R_{T} 2_{Z}-R_{0} 2}{\alpha \cdot R_{0} 2}
$$

where $R_{0} 2=53 \Omega$;

7. To calculate the temperatures of the first zone $T_{1 Z}$ and MTC $T_{G T}$ before the first zone heating, and also the temperatures of the first zone $T_{1 Z Z}$ and MTC $T_{G T Z}$ after the first zone heating, respectively by the approximate formulas

$$
\begin{aligned}
& T_{1 Z}=E_{1 Z} / S+T_{V K}, \quad T_{G T}=E_{G T} / S+T_{V K}, \\
& T_{1 Z Z}=E_{1 Z Z} / S+T_{V K Z}, T_{G T Z}=E_{G T Z} / S+T_{V K Z},
\end{aligned}
$$

where $S=42 \mu \mathrm{V}$ is the sensitivity of the type $\mathrm{K}$ thermocouples which are used in the prototype of TCPTF;

8. To calculate the temperatures of the passive thermostat before heating the first zone $T_{P T}$ and after its heating $T_{P T Z}$, respectively by the formulas

$$
T_{P T}=\frac{R_{T} 1-R_{0} 1}{\alpha \cdot R_{0} 1}, \quad T_{P T Z}=\frac{R_{T} 1_{Z}-R_{0} 1}{\alpha \cdot R_{0} 1},
$$

where $R_{0} 2=100 \Omega$;

9. To find the changes of the temperature during the time of heating for the first zone. $\Delta T_{1 Z}=T_{1 Z Z}-T_{1 Z}$, for the main thermocouple, $\Delta T_{G T}=T_{G T Z}-T_{G T}$ and for the passive thermostat, $\Delta T_{P T}=T_{P T Z}-T_{P T}$, respectively;

10. The temperature change of the measuring junction of MTC during the heating time of the first zone $\Delta T_{G T}$ caused by the change of the temperature of its environment, that means by the temperature changes of the passive thermostat $\Delta T_{P T}$, and actually by the error of method of TCPTF $\Delta_{M E T}$. From this $\Delta_{M E T}$ can be determined by the formula

$$
\Delta_{M E T}=\Delta T_{G T}-\Delta T_{P T}
$$

11. To find the temperature $T$, for which the combined maximum permissible error of MTC and the thermocouple of the first zone $\Delta T_{T C S}$ is equal to the change of the temperature of the first zone $\Delta T_{1 Z}$, from (8).
Apparently, as it is defined in point 10 of the above mentioned instruction, the value of $\Delta_{M E T}$ is calculated according to (9) as the difference, and the terms of (9) are calculated in point 9 , also as the differences. In addition, it is clear that changes in temperatures $\Delta T_{G T}$ and $\Delta T_{P T}$ will be small. This means that systematic error of measurement results of individual channels (see points 2 and 4 above) are virtually identical and will mutually adjust when calculating the differences. Thus the measurement results will be mostly affected by the random errors, rather short-term instability of the measurement results.

The apparatus for the experimental studies was especially designed with taking into account the need for providing accurate relative measurements, so there was theoretically estimated and experimentally investigated a short-term (diurnal) instability of the results of its measurements not exceeding $\pm(0.0005+0.002(\mathrm{X} / \mathrm{Xmax}-1)) \%$ in the measuring range from 0 to $80 \mathrm{mV}$, that is $\pm 2 \mu \mathrm{V}$.

To assess the error of the experimental research of error of method it is necessary to determine the sensitivity of all measuring channels. This can be done when knowing the voltage drops $U_{R N 1}$ and $U_{R N 2}$ across the reference resistors $R_{N} 1$ and $R_{N} 2$, respectively. As it is shown in Table 1. , presented in the next chapter, $U_{R N 1} \approx 40 \mathrm{mV}$, and $U_{R N 2} \approx 70 \mathrm{mV}$. As per the values $R_{N} 1=160.7 \Omega$ and $R_{N} 2=109.83 \Omega$, the currents through $R_{T} 1$ and $R_{T} 2$ will be equal to $I 1=U_{R N 1} / R_{N} 1 \approx 0.25 m A$ and $I 2=U_{R N 2} / R_{N} 2 \approx 0.65 \mathrm{~mA}$, respectively. The change in voltage drops across them per degree of temperature change (sensitivity) will be $S_{T} 1=I_{T} 1 \cdot \alpha \cdot R_{0} 1 \approx 0.1 \mathrm{mV} /{ }^{\circ} \mathrm{C}$ and $S_{T} 2=I_{T} 2 \cdot \alpha \cdot R_{0} 2 \approx 0.13 \mathrm{mV} /{ }^{\circ} \mathrm{C}$, respectively. When instability of the measuring channel of voltage is $\Delta_{U}= \pm 2 m k V$ (see the paragraph above), then the random error of measurement of temperatures of the passive thermostat and the reference junctions will be $\Delta_{R T 1}=\Delta_{U} / S_{T} 1 \approx 0.02^{\circ} \mathrm{C}$ and $\Delta_{R T 2}=\Delta_{U} / S_{T} 2 \approx 0.015^{\circ} \mathrm{C}$, respectively. The random error of the thermo-emf measurement of MTC will be $\Delta_{E}=\Delta_{U} / S \approx 0.05^{\circ} \mathrm{C}$.

It should be noted that the error of temperature measurement of the reference junctions $\Delta_{R T 2}$ only indirectly affects the result of the temperature change measurements by the main thermocouple, in addition, it is much lower than the random error of the thermo-emf measurement $\Delta_{E}$, that is why it is neglected.

The total random error of the error of method will be

$$
\Delta \Delta_{M E T}=\sqrt{\Delta_{E}^{2}+\Delta_{E}^{2}+\Delta_{R T 1}^{2}+\Delta_{R T 1}^{2}} \approx 0.075^{\circ} \mathrm{C}
$$

representing a significant percentage of the value of the error of method found in its theoretical estimation (see Fig.3.). Therefore, it is reasonable to hold several separate experiments to determine the convergence of the measurement results. 
Table 1. The results of the measurements and calculations in the study of the error of method of TCPTF.

\begin{tabular}{|c|c|c|c|c|c|c|}
\hline $\begin{array}{l}\text { Stage of the } \\
\text { instruction }\end{array}$ & $\begin{array}{l}\text { Measured } \\
\text { quantities }\end{array}$ & $\begin{array}{l}\text { Experiment } \\
\# 1\end{array}$ & $\begin{array}{l}\text { Experiment } \\
\# 2\end{array}$ & $\begin{array}{l}\text { Experiment } \\
\# 3\end{array}$ & $\begin{array}{l}\text { Experiment } \\
\# 4\end{array}$ & $\begin{array}{l}\text { Experiment } \\
\# 5\end{array}$ \\
\hline \multirow{7}{*}{2} & $T_{S},{ }^{\circ} \mathrm{C}$ & 19.76 & 18.66 & 18.72 & 18.72 & 20.88 \\
\hline & $U_{R N 1}, \mu \mathrm{V}$ & 43828 & 43812 & 43816 & 43821 & 43822 \\
\hline & $U_{R T 1}, \mu \mathrm{V}$ & 29741 & 29678 & 29682 & 29691 & 29699 \\
\hline & $U_{R N 2}, \mu \mathrm{V}$ & 75043 & 75121 & 75119 & 75113 & 75110 \\
\hline & $U_{R T 2}, \mu \mathrm{V}$ & 39262 & 39133 & 39141 & 39137 & 39144 \\
\hline & $E_{1 Z}, \mu \mathrm{V}$ & 8 & 4 & 4 & 4 & 4 \\
\hline & $E_{G T}, \mu \mathrm{V}$ & 0 & 0 & 0 & 0 & 0 \\
\hline \multirow{7}{*}{4} & $T_{S Z},{ }^{\circ} \mathrm{C}$ & 21.26 & 21.03 & 20.96 & 20.85 & 20.88 \\
\hline & $U_{R N 1 Z}, \mu \mathrm{V}$ & 43775 & 43732 & 43741 & 43748 & 43743 \\
\hline & $U_{R T 1 Z}, \mu \mathrm{V}$ & 29838 & 29787 & 29793 & 29788 & 29793 \\
\hline & $U_{R N 2 Z}, \mu \mathrm{V}$ & 75012 & 75002 & 75008 & 75011 & 75017 \\
\hline & $U_{R T 2 Z}, \mu \mathrm{V}$ & 39477 & 39436 & 39428 & 39413 & 39421 \\
\hline & $E_{1 Z Z}, \mu \mathrm{V}$ & 215 & 211 & 217 & 210 & 206 \\
\hline & $E_{G T Z}, \mu \mathrm{V}$ & 71 & 79 & 79 & 74 & 75 \\
\hline \multirow{4}{*}{5} & $R_{T} 1, \Omega$ & 109.05 & 108.86 & 108.86 & 108.82 & 108.91 \\
\hline & $R_{T} 2, \Omega$ & 57.46 & 57.21 & 57.23 & 57.23 & 57.24 \\
\hline & $R_{T} 1_{Z}, \Omega$ & 109.54 & 109.46 & 109.46 & 109.42 & 109.45 \\
\hline & $R_{T} 2_{Z}, \Omega$ & 57.80 & 57.75 & 57.73 & 57.71 & 57.72 \\
\hline \multirow{2}{*}{6} & $T_{V K},{ }^{\circ} \mathrm{C}$ & 19.76 & 18.66 & 18.72 & 18.72 & 18.77 \\
\hline & $T_{V K Z},{ }^{\circ} \mathrm{C}$ & 21.26 & 21.03 & 20.96 & 20.85 & 20.88 \\
\hline \multirow{4}{*}{7} & $T_{1 Z},{ }^{\circ} \mathrm{C}$ & 19.95 & 18.76 & 18.82 & 18.81 & 18.87 \\
\hline & $T_{G T},{ }^{\circ} \mathrm{C}$ & 19.76 & 18.66 & 18.72 & 18.72 & 18.77 \\
\hline & $T_{1 Z Z},{ }^{\circ} \mathrm{C}$ & 26.38 & 26.06 & 26.13 & 25.85 & 25.79 \\
\hline & $T_{G T Z},{ }^{\circ} \mathrm{C}$ & 22.95 & 22.91 & 22.84 & 22.61 & 22.67 \\
\hline \multirow{2}{*}{8} & $T_{P T},{ }^{\circ} \mathrm{C}$ & 21.24 & 20.79 & 20.80 & 20.85 & 20.91 \\
\hline & $T_{P T Z},{ }^{\circ} \mathrm{C}$ & 22.39 & 22.20 & 22.20 & 22.11 & 22.19 \\
\hline \multirow{3}{*}{9} & $\Delta T_{1 Z},{ }^{\circ} \mathrm{C}$ & 6.43 & 7.30 & 7.31 & 7.04 & 6.92 \\
\hline & $\Delta T_{G T},{ }^{\circ} \mathrm{C}$ & 1.69 & 1.88 & 1.88 & 1.76 & 1.79 \\
\hline & $\Delta T_{P T},{ }^{\circ} \mathrm{C}$ & 1.15 & 1.41 & 1.40 & 1.26 & 1.27 \\
\hline 10 & $\Delta T_{1},{ }^{\circ} \mathrm{C}$ & 4.93 & 4.93 & 5.07 & 4.91 & 4.81 \\
\hline 11 & $T,{ }^{\circ} \mathrm{C}$ & 465 & 465 & 478 & 463 & 453 \\
\hline 12 & $\Delta_{M E T},{ }^{\circ} \mathrm{C}$ & 0.54 & 0.47 & 0.49 & 0.50 & 0.51 \\
\hline
\end{tabular}

\section{THE RESULTS OF THE EXPERIMENTAL RESEARCH}

Fig.5. shows experimental arrangement to research the error of method. It shows the passive thermostat of the measuring junction of MTC, the first zone of TCPTF (heater H1) and power supply of the RTD of the passive thermostat of measuring junction of MTC. All thermocouples of the investigated TCPTF (MTC and TC1 ... TC9) are type K (their legs are made of chromel and alumel). Because of the difficulties of machining stainless steels [34], [35] which are resistant to high temperatures, the thermowell of MTC and other constructive elements of the studied prototype are made of regular constructional steel.
For RTD measurement there is used the potentiometer circuit with its four-lead arrangement. The results of the measurements and calculations, described in the instruction of the experimental research, are presented in Table 1. As it is seen from Table 1., five experiments have been conducted, their results differ little so the censorship is not required.

Values of the found error of method are given in Table 1. line 10 , and in line 12 - the temperature changes of the heater $\mathrm{H} 1$ relative to the ambient temperature changes, found as $\Delta T_{1}=\Delta T_{1 Z}-\left(\Delta T_{S Z}-\Delta T_{S}\right)$. In line 11 the temperatures $T$ are given, which correspond to the total 
permissible error of the type $\mathrm{K}$ thermocouples MTC and $\mathrm{TC} 1$, equal to the temperature change of the first zone $\Delta T_{1}$ in each experiment. The value of $T$ is calculated according to (8), provided that the errors of MTC and TC1 are equal and independent, and their total error is calculated as the square root of the sum of squares of their individual errors [36]. As a result of the conversion (1) we obtain

$$
\Delta T_{T C}=\frac{\Delta T_{T C S}}{\sqrt{2}}
$$

Then we plug the values obtained in (11) to (8) and solve (8) for $T$ for each experiment.

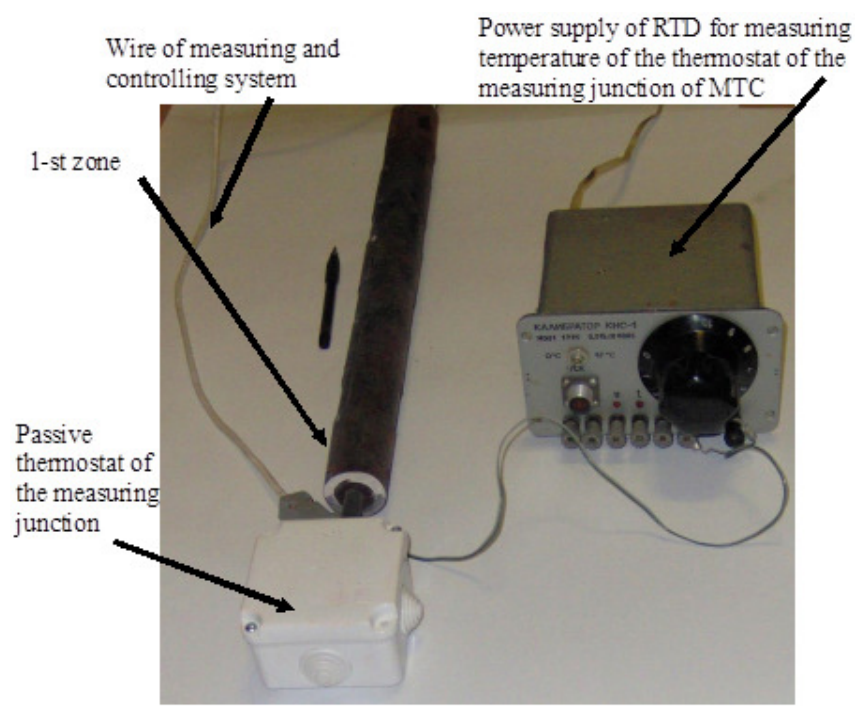

Fig.5. Experimental arrangement.

As can be seen from Table 1., the values of the error of method of TCPTF found experimentally have relatively small spread (no more than $\pm 8 \%$ ) relative to the mean value, and their absolute values do not exceed values estimated according to (10) error of the error of method $\Delta \Delta_{M E T}$. Therefore, it can be considered that the convergence of the experimental results is good enough, the results themselves are correct and can be compared with the results of the theoretical assessment of the error of method.

\section{COMPARISON OF THE THEORETICAL AND EXPERIMENTAL STUDIES}

Parameters of the studied TCPTF, required for the estimation of the theoretical value of the error method $\Delta_{M E T}^{T}$, are given in (5) except the thermal conductivity of the thermowell. The thermowell of the prototype is made of structural steel whose thermal conductivity is

$$
\lambda=47 \frac{W}{m \times K}
$$

where $\lambda-$ thermal conductivity of the thermowell material of the MTC [32].
Let us find for the values of the changes of the temperature of the first zone $\Delta T_{1 Z}$, which are given in Table 1., the theoretical values of the error of method. Obtained results are summarized in Table 2. Given there are the temperatures $T$, which correspond to the total permissible errors of MTC and TC1 of type K (row 11 of Table 1.), experimentally obtained values of the error of method $\Delta_{M E T}$ and theoretical values of the error of method $\Delta_{M E T}^{T}$. In the last line of Table 2. there are shown the deviations of values of the error of method obtained experimentally from their corresponding values, found theoretically.

$$
\Delta \Delta_{M E T}^{E}=\Delta_{M E T}-\Delta_{M E T}^{T}
$$

Apparently, obtained experimental and theoretical values $\Delta \Delta_{M E T}^{E}$ are commensurate with random error of the equipment, estimated in chapter 5. From the above mentioned, we can conclude that:

1. experimental studies are conducted correctly;

2. error of method of TCPTF is quite small even when the structural steel is used.

Since the method of estimation of the error of method is confirmed by the results of experiment, it can be used to estimate the error of method of TCPTF, whose thermowell is made of high-alloyed stainless steel resistant to corrosion at high temperatures. For the experimental conditions the error of method of the studied prototype will not exceed $0.13{ }^{\circ} \mathrm{C}$, this is negligible even during measurement with the highest accuracy exemplary thermocouples.

Table 2. Results of the comparison of the experimental and theoretical values of the error of method.

\begin{tabular}{|c|c|c|c|c|c|}
\hline $\begin{array}{c}\text { Physical } \\
\text { quantities }\end{array}$ & $\begin{array}{c}\text { Expe- } \\
\text { riment } \\
\# \mathbf{1}\end{array}$ & $\begin{array}{c}\text { Expe- } \\
\text { riment } \\
\mathbf{\# 2}\end{array}$ & $\begin{array}{c}\text { Expe- } \\
\text { riment } \\
\mathbf{\# 3}\end{array}$ & $\begin{array}{c}\text { Expe- } \\
\text { riment } \\
\mathbf{\# 4}\end{array}$ & $\begin{array}{c}\text { Expe- } \\
\text { riment } \\
\mathbf{\# 5}\end{array}$ \\
\hline$T,{ }^{\circ} \mathrm{C}$ & 465 & 465 & 478 & 463 & 453 \\
\hline$\Delta_{M E T},{ }^{\circ} \mathrm{C}$ & 0.54 & 0.47 & 0.49 & 0.50 & 0.51 \\
\hline$\Delta_{M E T}^{T},{ }^{\circ} \mathrm{C}$ & 0.40 & 0.40 & 0.41 & 0.40 & 0.39 \\
\hline$\Delta \Delta_{M E T}^{E},{ }^{\circ} \mathrm{C}$ & 0.14 & 0.07 & 0.08 & 0.10 & 0.12 \\
\hline
\end{tabular}

\section{CONCLUSIONS}

Experimental studies of the error of method of TCPTF, the results of which are shown in this paper have shown that:

1. The proposed technique of the experimental studies based on measuring the changes in temperature during the experiment (relative measurements) enables accurate enough study of the error of method of TCPTF, which is caused by the heat flux from the auxiliary heaters of TCPTF toward the measuring junction of MTC. The obtained results of the experimental researches converge well with the theoretical ones. It enables us to think that the theoretical researches are correct;

2. The proposed method of theoretical assessment of the error of method of TCPTF can be considered quite correct, despite the simplified model of thermal processes. Deviation of the values of the error of method, found using the 
proposed method of experiment from the values found experimentally, is more than three times less than the errors of exemplary thermocouples that can be used for calibration of TCPTF. So, the proposed method of the experiment can be used for the practical purposes;

3. The correctness of the proposed method of the theoretical estimation of error of method of TCPTF shows the way of reducing this error by increasing the thermowell heat transfer area by applying either grooves or thread, or mount additional fins on the end of the thermowell.

As it has been shown in this paper, the error of method is quite small, therefore it is necessary to study the other errors of TCPTF. Also it is worth optimizing the design of TCPTF.

\section{ACKNOWLEDGMENT}

This work was supported by Natural Science Foundation of Hubei Province of China (2014CFB605), Foundation of Wuhan Science and technology Bureau (2015030809020370), Doctoral Scientific Research Fund from Hubei University of Technology (No. BSQD14037).

\section{REFERENCES}

[1] Lutsyk, Y., Hook, O., Lakh, O., Stadnyk, B. (2006). Temperature Measurements: Theory and Practice. Lviv, Ukraine: Beskyd Bit. (in Ukrainian)

[2] Webster, J. (1999). Measurement, Instrumentation, and Sensors Handbook. CRC Press.

[3] Habisreuther, T., Elsmann, T., Pan, Z., Graf, A., Willsch, R., Schmidt, M.A. (2015). Sapphire fiber Bragg gratings for high temperature and dynamic temperature diagnostics. Applied Thermal Engineering, 91, 860-865.

[4] Yi, X., Liu, C. (2009). Development of high-precision temperature measurement system based on ARM. In Proceedings of 9th International Conference on Electronic Measurement and Instruments, 16-19 August, 2009, Beijing, China. IEEE, 795-799.

[5] Kočí, V., Kočí, J., Korecký, T., Maděra, J., Černý, R. (2015). Determination of radiative heat transfer coefficient at high temperatures using a combined experimental-computational technique. Measurement Science Review, 15 (2), 85-91.

[6] Glowacz, A., Glowacz, A., Glowacz, Z. (2015). Recognition of thermal images of direct current motor with application of area perimeter vector and bayes classifier. Measurement Science Review, 15 (3), 119126.

[7] Sloneker, K.C. (2009). Thermocouple inhomogeneity. Ceramic Industry, 159 (4), 13-18.

[8] Körtvélyessy, L. (1981). Thermoelement Praxis. Essen, Germany: Vulkan-Verlag. (in German)

[9] Glowacz, A., Glowacz, A., Korohoda, P. (2014). Recognition of monochrome thermal images of synchronous motor with the application of binarization and nearest mean classifier. Archives of Metallurgy and Materials, 59 (1), 31-34.

[10] Park, R.M. (ed.) (1993). Manual on the Use of Thermocouples in Temperature Measurement. ASTM International.
[11] Abdelaziz, Y., Edler, F. (2009) A method for evaluation of the inhomogeneity of thermoelements. Measurement Science and Technology, 20 (5), 055102.

[12] Pearce, J.V. (2007). Quantitative determination of the uncertainty arising from the inhomogeneity of thermocouples. Measurement Science and Technology, 18, 3489-3495.

[13] Tamba, J., Yamazawa, K., Masuyama, S., Ogura, H., Izuchi, M. (2011). Evaluating the inhomogeneity of thermocouples using a pressure-controlled water heat pipe. International Journal of Thermophysics, 32, 2436-2451.

[14] Webster, E.S., White, D.R., Edgar, H. (2015). Measurement of inhomogeneities in MIMS thermocouples using a linear-gradient furnace and dual heat-pipe scanner. International Journal of Thermophysics, 36, 444-466.

[15] Su Jun, Kochan, O. (2014). The mechanism of the occurrence of acquired thermoelectric inhomogeneity of thermocouples and its effect on the result of temperature measurement. Measurement Techniques, 57 (10), 1160-1166.

[16] Körtvélyessy, L. (1998). Thermoelement Praxis : Neue theoretische Grundlagen und deren Umsetzung, 3rd ed. Essen, Germany: Vulkan-Verlag. (in German)

[17] Holmsten, M., Ivarsson, J., Falk, R., Lidbeck, M., Josefson, L.-E. (2008). Inhomogeneity measurements of long thermocouples using a short movable heating zone. International Journal of Thermophysics, 29 (3), 915-925.

[18] Isotermal Technology Ltd. (1999). Temperature calibration with isotech block baths.

[19] Buschfort, H.G., Hundere, A. (1968). Self-calibrating temperature sensing probe and probe - indicator combination. U.S. Patent 3,499,340. Washington, D.C.: U.S. Patent and Trademark Office.

[20] Sachenko, A., Kochan, V., Turchenko, V. (2000). Sensor drift prediction using neural networks. In Proceedings of International Workshop on Virtual and Intelligent Measurement Systems (VIMS'2000), 29-30 April, 2000, Annapolis, USA, 88-92.

[21] Zvizdic, D., Sestan, D. (2015). Zinc-filled multientrance fixed point. International Journal of Thermophysics, 36, 336-346.

[22] Su Jun, Kochan, O. (2014). Investigations of thermocouple drift irregularity impact on error of their inhomogeneity correction. Measurement Science Review, 14 (1), 29-34.

[23] White, W.P. (1906). The constancy of thermoelements. Physical Review, 23, 449-474.

[24] Roeser, W., Wensel, H. (1935). Methods of testing thermocouples and thermocouple materials. Journal of Research of the National Bureau of Standards, 14, 247-282.

[25] Hill, K.D., Gee, D.J. (2012). Quantifying the calibration uncertainty attributable to thermocouple inhomogeneity. In Proceedings of the 9th International Temperature Symposium Temperature: 
Its Measurement and Control in Science and Industry, 19-23 March, 2012, Los Angeles, USA. AIP 1552, vol. 8, 520- 525 .

[26] Failleau. G., Elliott, C.J., Deuzé, T., Pearce, J.V., Machin, G., Sadli, M. (2014). Miniature fixed-point cell approaches for in situ monitoring of thermocouple stability. International Journal of Thermophysics, 35, 1223-1238.

[27] Strnad, R., Jelínek, M., Failleau, G., et al. (2014). Drift a doba života termoelektrických článků při vysokých teplotách. Automa, 6, 28-31. (in Czech)

[28] Kochan, O., Kochan, R., Bojko, O., Chyrka, M. (2007). Temperature measurement system based on thermocouple with controlled temperature field. In Proceedings of the 4th IEEE International Workshop IDAACS'2007, 6-8 September, 2007, Dortmund, Germany. IEEE, 47-51.

[29] International Electrotechnical Commission. (1989). Thermocouples. Part 2: Tolerances. IEC 584-2.

[30] Lienhard, J.H. V., Lienhard, J.H. IV. (2008). A Heat Transfer Textbook. Cambridge: Phlogiston Press.

[31] Su Jun, Kochan, O., Kochan, R. (2015). Evaluation of error of method of thermocouple with controlled profile of temperature filed. In Proceedings of the 10th International Conference on Measurement (Measurement 2015), 25-28 May 2015, Smolenice, Slovakia. Bratislava, Slovakia: IMS SAS, 301-304.
[32] Kuchling, H. (1980). Taschenbuch der Physik. Leipzig: VEB Fachbuchferlag. (in German)

[33] Glowacz, A., Glowacz, A., Glowacz, Z. (2014). Recognition of monochrome thermal images of synchronous motor with the application of quadtree decomposition and backpropagation neural network. Eksploatacja $i$ Niezawodnosc - Maintenance and Reliability, 16 (1), 92-96.

[34] Krolczyk, G.M., Legutko, S. (2014). Experimental analysis by measurement of surface roughness variations in turning process of duplex stainless steel. Metrology and Measurement Systems, 21 (4), 759770.

[35] Hreha, P., Radvanska, A., Knapcikova, L., Krolczyk, G.M., Legutko, S., Krolczyk, J., Hloch, S., Monka, P. (2015). Roughness parameters calculation by means on-line vibration monitoring emerging from AWJ interaction with material. Metrology and Measurement Systems, 22 (2), 315-326.

[36] Hughes, I.G., Hase, T.P.A. (2010). Measurements and Their Uncertainties. A Practical Guide to Modern Error Analysis. Oxford University Press.

Received September 19, 2015. Accepted December 1, 2015. 